\title{
Mesoporous carbons synthesized by direct carbonization of citrate salts for use as high-performance capacitors
}

\author{
G. A. Ferrero, M. Sevilla, A. B. Fuertes \\ Instituto Nacional del Carbón (CSIC), P.O. Box 73, Oviedo 33080, Spain
}

\section{Abstract}

A simple one-step synthesis methodology for the fabrication of mesoporous carbons with an excellent performance as supercapacitor electrodes is presented. The procedure is based on the carbonization of non-alkali organic salts such as citrate salts of iron, zinc or calcium. The carbonized products contain numerous inorganic nanoparticles (i.e. $\mathrm{Fe}, \mathrm{ZnO}$ or $\mathrm{CaO}$ ) embedded within a carbonaceous matrix. These nanoparticles act as endotemplate, which when removed, leaves a mesoporous network. The resulting carbon samples have a large specific surface area up to $\sim 1600 \mathrm{~m}^{2} \mathrm{~g}^{-1}$ and a porosity made up almost exclusively of mesopores. An appropriate heat-treatment of these materials with melamine allows the synthesis of $\mathrm{N}$-doped carbons which have a high nitrogen content ( 8-9 wt \%), a large specific surface area and retain the mesoporous structure. The mesoporous carbon samples were employed as electrode materials in supercapacitors. They exhibit specific capacitances of 200-240 $\mathrm{F} \mathrm{g}^{-1}$ in $1 \mathrm{M} \mathrm{H}_{2} \mathrm{SO}_{4}$ and $100-130 \mathrm{~F} \mathrm{~g}^{-1}$ in EMImTFSI/AN. More importantly, the carbon samples possess a good capacitance retention in both electrolytes (> $50 \%$ in $\mathrm{H}_{2} \mathrm{SO}_{4}$ and $>80 \%$ in EMImTFSI/AN at $100 \mathrm{~A} \mathrm{~g}^{-1}$ ) owing

\footnotetext{
* Corresponding author. E-mail: abefu@incar.csic.es (A. B. Fuertes). Phone: +34 985119090
} 
to their mesoporous structure which facilitates the penetration and transportation of ions. 


\section{Introduction}

Porous carbons belong to a highly successful class of materials that have attracted increasing interest in recent years because of their potential use as components in supercapacitors [1, 2], Li-ion batteries and fuel cells [3], as carriers for gas storage (i.e. $\mathrm{H}_{2}, \mathrm{CH}_{4}, \mathrm{CO}_{2}$ ) [4], sorbents for air and water purification [5], and as catalysts or catalytic supports [6]. The importance of these materials lies in the fact that they are easily produced and can combine several significant properties: a) a good electronic conductivity, b) a high chemical stability, c) low cost and high availability, and d) a large surface area and porosity [7]. Porous carbons are currently obtained by the carbonization of organic precursors (natural or synthetic), followed by physical or chemical activation processes. The materials produced in this way have a porosity made up almost exclusively of narrow pores; i.e. micropores in the case of the carbons produced by physical activation or micropores and small mesopores for those obtained through chemical activation [8]. However, for a certain number of potential applications, such as those involving the manipulation (i.e. immobilization, adsorption and recognition) of bulky molecules (i.e. biomolecules or dyes) or those that require the enhanced transport of species within the pore network, large mesopores would be preferable to narrow pores (i.e. micropores and small mesopores). Unfortunately, carbons with a porous structure formed exclusively by mesopores cannot be synthesized by means of the classical methods used for preparing active carbons. Several synthesis strategies have been adopted to prepare mesoporous carbons, including the carbonization of polymer blends, catalytic activation using metal species, 
carbonization of organic aerogels or nanocasting methods [9-11]. The nanocasting techniques based on the use of hard or soft templates to fabricate mesoporous carbons have emerged as a powerful alternative for producing these types of materials [12]. However, these procedures which rely on the fabrication of sacrificial templates (i.e. mesoporous silica or surfactants) are expensive, complicated, and time-consuming, and consequently they are unsuitable for large-scale production and industrial applications. For these reasons, the preparation of mesoporous carbons by a facile, cost-effective and sustainable method is still a challenge to be overcome. In the last years, several reports have appeared showing the production of porous carbons by the carbonization of organic salts such as ethylenediamine tetraacetic acid disodium magnesium [13], alkali chloroacetates [14] or citrate salts $[15,16]$. However, these works do not provide a clear image either of the general scope of the procedure or of the activation mechanism responsible for the generation of porosity.

Recently, we presented a rational description of the production of porous carbons by the carbonization of certain organic salts. More specifically, we proposed a consistent mechanism to explain how carbons with a large number of micropores can be produced by means of the direct carbonization of alkali organic salts [17]. These compounds combine a carbon precursor (i.e. the organic moiety) and certain elements (i.e. Na or K) which during heat-treatment are converted into inorganic species that act as activating agents capable of generating micropores. This process takes place via a mechanism similar to that operating during the chemical activation of carbonaceous materials with alkali hydroxides (i.e. $\mathrm{KOH}$ and $\mathrm{NaOH}$ ). The porous carbons obtained in this 
way exhibit a high performance as electrochemical capacitors, as we recently showed in relation to the interconnected microporous carbon nanosheets obtained by the direct carbonization of potassium citrate [18] or carbon nanosheets with a hierarchical porosity produced by the carbonization of sodium gluconate [19]. In this paper, we show that this general one-step synthesis scheme can be extended to the production of mesoporous carbons. Indeed, as in the fabrication of microporous carbons, the production of mesoporous carbons was also carried out by means of a simple one-step methodology consisting in the direct carbonization of certain commercial organic salts without any complicated processes or the addition of any foreign substance. The key point of our synthesis strategy towards mesoporous carbons is the use of organic salts formed by an organic moiety and non-alkali elements which do not react with the carbonaceous matrix during the carbonization process and, thereby, they are unable to act as activating agents. In this way, unlike the synthesis of microporous carbons by direct carbonization of alkali organic salts, this process does not entail any activation reaction. However, during the carbonization step, these elements gives rise to the corresponding oxide or metallic nanoparticles which are embedded within the carbonaceous matrix and operate as endotemplate nanoparticles that give rise to the formation of mesopores once they are removed. Our main purpose in the present work is to demonstrate the viability of this general synthesis scheme. In this sense, as a proof-of-concept we used three citrate salts (i.e. citrates of iron, zinc and calcium) as precursor of mesoporous carbons. In addition, we show a simple strategy for introducing nitrogen functional groups into the mesoporous carbons produced by this method. The effectiveness of undoped and $\mathrm{N}$-doped 
mesoporous carbons as electrochemical supercapacitors was tested in aqueous $\left(1 \mathrm{M} \mathrm{H}_{2} \mathrm{SO}_{4}\right)$ and ionic liquid (EMImTFSI) electrolytes.

\section{Experimental Section}

\subsection{Synthesis of Materials}

In a typical synthesis procedure, $3 \mathrm{~g}$ of citrate salt (i.e. $\left(\mathrm{C}_{6} \mathrm{H}_{5} \mathrm{O}_{7}\right)_{2} \mathrm{Zn}_{3} \cdot 2 \mathrm{H}_{2} \mathrm{O}$, $\left(\mathrm{C}_{6} \mathrm{H}_{5} \mathrm{O}_{7}\right)_{2} \mathrm{Ca}_{3} \cdot 4 \mathrm{H}_{2} \mathrm{O}$ or $\left.\left(\mathrm{C}_{6} \mathrm{H}_{5} \mathrm{O}_{7}\right) \mathrm{Fe} \cdot \mathrm{xH}_{2} \mathrm{O}\right)$, purchased from Aldrich, was heattreated in a stainless steel reactor under nitrogen up to $800^{\circ} \mathrm{C}$ at a heating rate of $3{ }^{\circ} \mathrm{C} / \mathrm{min}$ and held at this temperature for 1 hour. The resulting black solid was then washed with diluted $\mathrm{HCl}(10 \%)$. Finally, the carbon was collected by filtration, washed with abundant distilled water and dried at $120{ }^{\circ} \mathrm{C}$ for several hours. The carbon samples were denoted as $C X-800$, where $X$ indicates the type of citrate salt $(X=F e, Z n$ or $\mathrm{Ca})$.

For the preparation of the $\mathrm{N}$-doped samples, typically $0.2 \mathrm{~g}$ of mesoporous carbon was mixed with $0.8 \mathrm{~g}$ of melamine (in a melamine/carbon weight ratio of 4) and the mixture was heat treated under nitrogen up to $800^{\circ} \mathrm{C}$ (at a heating rate of $3^{\circ} \mathrm{C} / \mathrm{min}$ ) for 1 hour. The $\mathrm{N}$-doped samples are denoted as CX-800-N.

\subsection{Physical characterization}

Scanning electron microscopy (SEM) images were obtained on a Quanta FEG650 (FEI) instrument, whereas transmission electron microscopy (TEM) images were recorded on a JEOL (JEM 2100-F) apparatus operating at $200 \mathrm{kV}$. The nitrogen sorption isotherms of the carbon samples were measured at -196 ${ }^{\circ} \mathrm{C}$ using a Micromeritics ASAP 2020 sorptometer. The apparent surface area was calculated by the BET method. An appropriate relative pressure range was 
selected to ensure that a positive line intersect of multipoint BET fitting $(C>0)$ would be obtained and $\mathrm{V}_{\text {ads }}\left(1-\mathrm{p} / \mathrm{p}_{\mathrm{o}}\right)$ would increase with $\mathrm{p} / \mathrm{p}_{\mathrm{o}}$ [20]. The total pore volume $\left(V_{p}\right)$ was determined from the amount of nitrogen adsorbed at a relative pressure $\left(p / p_{0}\right)$ of 0.95 . The micropore volume $\left(V_{\text {micro }}\right)$ was estimated using the $\alpha_{s}$-plot method. The reference adsorption data used for the $\alpha_{s}$ analysis of the carbon samples correspond to a non-graphitized carbon black sample [21]. The primary mesopore volume $\left(V_{\text {meso }}\right)$ was determined from the difference between the pore volume $\left(\mathrm{V}_{\mathrm{p}}\right)$ and the micropore volume $\left(\mathrm{V}_{\mathrm{mi}}\right)$. The pore size distribution (PSD) was calculated by means of the Kruk-Jaroniec-Sayari method [22].

X-ray diffraction (XRD) patterns were obtained on a Siemens D5000 instrument operating at $40 \mathrm{kV}$ and $20 \mathrm{~mA}$, using CuK $\alpha$ radiation. Thermogravimetric analysis (TGA) curves were recorded on a $\mathrm{Cl}$ Electronics Instruments system. X-ray photoelectron spectroscopy (XPS) was performed on a Specs

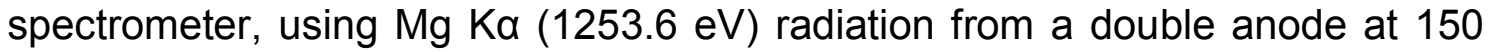
W. Elemental analysis ( $\mathrm{C}, \mathrm{N}$ and $\mathrm{O})$ of the samples was carried out on a LECO CHN-932 microanalyzer. The dc electrical conductivity of the carbon powders was determined on a home-made apparatus (four-probe method) by pressing the powders between two plungers, into a hollow Nylon cylinder (inner diameter of $8 \mathrm{~mm}$ ), and applying a pressure of $7.1 \mathrm{MPa}$.

\subsection{Electrochemical measurements}

The electrodes were prepared by mixing 85 wt \% active material, 10 wt \% polytetrafluoroethylene (PTFE) binder (Aldrich, 60 wt \% suspension in water) and 5 wt $\%$ conductive additive Super C65 (Timcal company). The electrochemical measurements were performed in two-electrode Swagelok type 
cells. Electrochemical capacitors were assembled using two carbon electrodes of similar mass and thickness $(\sim 100-150 \mu \mathrm{m})$, electrically isolated by a glassy fibrous separator. Stainless steel current collectors were used with the ionic liquid 1-Ethyl-3-methylimidazolium bis(trifluoromethylsulfonyl)imide (EMImTFSI) (purity $=99 \%$, lonic Liquids Technology, Germany) dissolved in acetonitrile (AN, 99.8\%, anhydrous, Sigma-Aldrich) electrolyte. Gold current collectors were employed with $1 \mathrm{M} \mathrm{H}_{2} \mathrm{SO}_{4}$ electrolyte. To evaluate the polarization characteristics of the positive and the negative electrode independently, a special two-electrode cell provided with a reference electrode $\mathrm{Hg} / \mathrm{Hg}_{2} \mathrm{SO}_{4}(\mathrm{SME}$, saturated) was used. The electrochemical characterization was performed using a computer controlled potentiostat (Biologic VMP3 multichannel generator) and consisted of cyclic voltammetry, galvanostatic charge-discharge cycling experiments and electrochemical impedance spectroscopy measurements. A commercial activated carbon commonly used in commercial supercapacitors (Supra DLC-50, Norit, $\mathrm{S}_{\mathrm{BET}}=1890 \mathrm{~m}^{2} \mathrm{~g}^{-1}$ ) was analyzed for comparison.

Cyclic voltammetry measurements were conducted between 0 and $3 \mathrm{~V}$ in an ionic liquid (EMImTFSI) mixed with acetonitrile (AN) (EMImTFSI/AN = 1:1 mass ratio), and between 0 and $1.2 \mathrm{~V}$ in $1 \mathrm{M} \mathrm{H}_{2} \mathrm{SO}_{4}$ at sweep rates ranging from 1 to $2000 \mathrm{mV} \mathrm{s}^{-1}$. Plots of specific capacitance vs. voltage for the conventional twoelectrode cell were calculated using the formula:

$$
\mathrm{C}_{\mathrm{sp}}=\frac{2 \cdot \mathrm{I}}{v \cdot \mathrm{m}}
$$

where $\mathrm{I}=$ current $(\mathrm{A}), \mathrm{v}=$ scan rate $\left(\mathrm{V} \mathrm{s}^{-1}\right)$ and $\mathrm{m}=$ mass (grams) of carbon material in one electrode. 
Galvanostatic charge/discharge tests were performed in the $0-3 \mathrm{~V}$ range in an EMImTFSI/acetonitrile medium and in the $0-1.2 \mathrm{~V}$ range in an aqueous medium at current densities in the 0.1 to $150 \mathrm{~A} \mathrm{~g}^{-1}$ range (based on the active mass of a single electrode). The specific gravimetric capacitance of a single electrode ( $F$ $\mathrm{g}^{-1}$ ) determined from the galvanostatic cycles was calculated by means of the formula

$$
C_{s p}=\frac{2 \cdot I}{(d V / d t) \cdot m}
$$

where $\mathrm{dV} / \mathrm{dt}=$ slope of the discharge curve $\left(\mathrm{V} \mathrm{s}^{-1}\right)$.

To trace the Ragone-like plots from the constant current discharge tests, the specific energy $\left(\mathrm{Wh} \mathrm{kg}^{-1}\right)$ and average power $\left(\mathrm{kW} \mathrm{kg}^{-1}\right)$ were calculated using the following formulae:

$$
\begin{aligned}
& E=\frac{1}{2} C_{\text {cell }} \Delta V_{d}^{2} \\
& P=\frac{E}{\Delta t_{d}}
\end{aligned}
$$

where $\mathrm{C}_{\text {cell }}$ is the gravimetric capacitance of the total cell, $\Delta \mathrm{V}_{\mathrm{d}}$ is the operation voltage $\left(V_{\max }-I R_{d r o p}\right)$ and $\Delta t_{d}$ is the discharge time.

Electrochemical impedance spectroscopy (EIS) measurements were carried out at open-circuit voltage (i.e., $0 \mathrm{~V}$ ) within the frequency range of $1 \mathrm{mHz}$ to 100 $\mathrm{kHz}$ and a $10 \mathrm{mV} \mathrm{AC}$ amplitude. Nyquist plots and plots of the dependence of capacitance on frequency were recorded to characterize the impedance of the tested samples. The specific gravimetric capacitance of a single electrode, $\mathrm{C}_{\mathrm{EIS}}$ $\left(F g^{-1}\right)$, was calculated from the following formula and normalized with respect to the specific gravimetric capacitance at $1 \mathrm{mHz}$ : 


$$
C_{E I S}=\frac{2 \cdot \mid \operatorname{Im}(\mathrm{Z})}{2 \pi \mathrm{f} \cdot\left[(\operatorname{Im}(\mathrm{Z}))^{2}+(\operatorname{Re}(\mathrm{Z}))^{2}\right] \cdot \mathrm{m}}
$$

where $f$ is the operating frequency $(\mathrm{Hz})$, and $\operatorname{Im}(\mathrm{Z})$ and $\operatorname{Re}(\mathrm{Z})$ are the imaginary and real components of the total device resistance $(\mathrm{Ohm})$. The relaxation time constant, $\tau_{0}$, which defines the boundary between the regions of capacitive and resistive behaviors of the supercapacitor, was deduced from the frequency $f_{0}$ as follows: $\tau_{0}=1 / f_{0}$, where $f_{0}$ can be obtained from the real capacitance plot at $C^{\prime}=$ $\mathrm{C}_{1 \mathrm{mHz}} / 2$.

\section{Results and Discussion}

\subsection{Thermal decomposition of citrate salts}

The mechanism of formation of the mesoporous carbons by the thermal decomposition of citrate salts was investigated by means of thermogravimetric analysis, as illustrated in Figure S1. In general, the decomposition occurs in three well-defined stages as reported by several authors in reference to calcium and iron citrates $[23,24]$. Thus, at temperatures below $320^{\circ} \mathrm{C}$ the dehydration of the salts occurs, whereas at intermediate temperatures $\left(\sim 350-500{ }^{\circ} \mathrm{C}\right)$ the pyrolysis of the organic moiety to carbon and the formation of inorganic species take place (i.e. $\mathrm{Fe}_{2} \mathrm{O}_{3}, \mathrm{CaCO}_{3}$ or $\mathrm{ZnCO}_{3}$ ). Finally at higher temperatures, the carbonates are decomposed into their corresponding oxides, whereas the iron oxide is reduced to Fe nanoparticles. Consequently, the resulting solid residue obtained after heat treatment at $800^{\circ} \mathrm{C}$ consists of inorganic nanoparticles (i.e. $\mathrm{Fe}, \mathrm{CaO}$ or $\mathrm{ZnO}$ ) embedded within a carbonaceous matrix. The presence of these inorganic species is clearly evidenced by means of XRD measurements carried out on the materials carbonized at $800{ }^{\circ} \mathrm{C}$ and at an intermediate 
temperature of $430^{\circ} \mathrm{C}$ for iron citrate and $500^{\circ} \mathrm{C}$ for calcium citrate (Figure 1). Indeed, the XRD diffraction patterns of the samples prepared at these intermediate temperatures clearly reveal the presence of $\mathrm{Fe}_{2} \mathrm{O}_{3}$ (Fig. 1a) and $\mathrm{CaCO}_{3}$ (Fig. 1c). Zinc carbonate was not detected because it rapidly transforms to $\mathrm{ZnO}$ (Figure $1 \mathrm{~b}$ ), as is illustrated by TGA analysis (Figure S1). In the case of the materials treated at $800{ }^{\circ} \mathrm{C}$, the $\mathrm{XRD}$ analysis shows that they contain nanoparticles of Fe (Fig. 1a), ZnO (Fig. 1b) and $\mathrm{CaO}$ (Fig. 1c) with crystallite sizes of $37 \mathrm{~nm}(\mathrm{Fe}), 22 \mathrm{~nm}(\mathrm{ZnO}), 18 \mathrm{~nm}(\mathrm{CaO})$, as deduced by the Scherrer equation. Bearing in mind that these inorganic particles are embedded within the carbonaceous matrix, it can be envisaged that once they have been removed by acid washing, the resulting carbon will contain numerous nanovoids in the mesopore range. This is the essence of our simple synthesis strategy for producing mesoporous carbons, an illustration of which is given in Figure 2. 

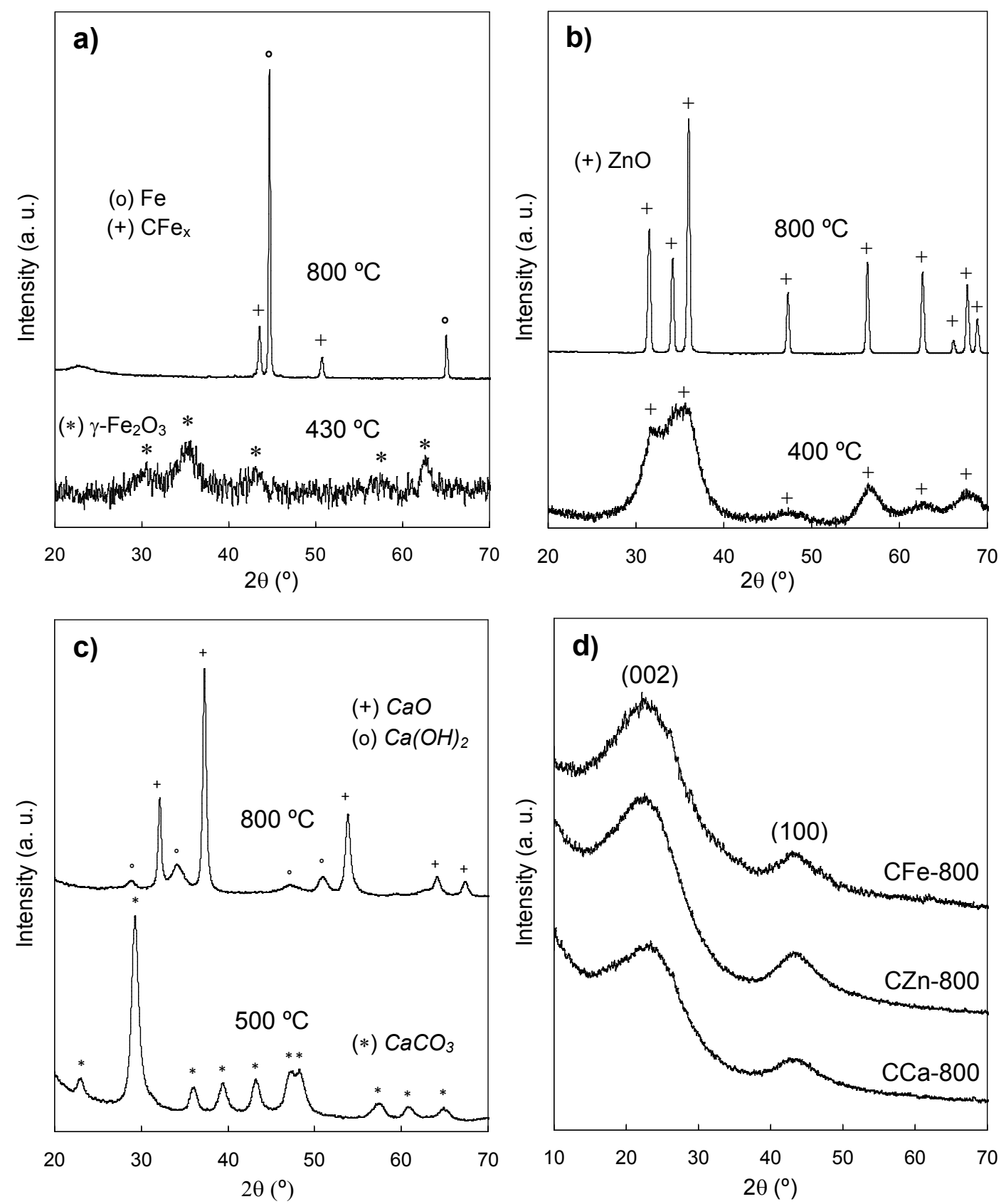

Figure 1. XRD patterns obtained for the citrate salts of (a) Fe, (b) $\mathrm{Zn}$ and (c) $\mathrm{Ca}$ at different carbonization temperatures, and (d) for the carbons synthesized at $800^{\circ} \mathrm{C}$. 


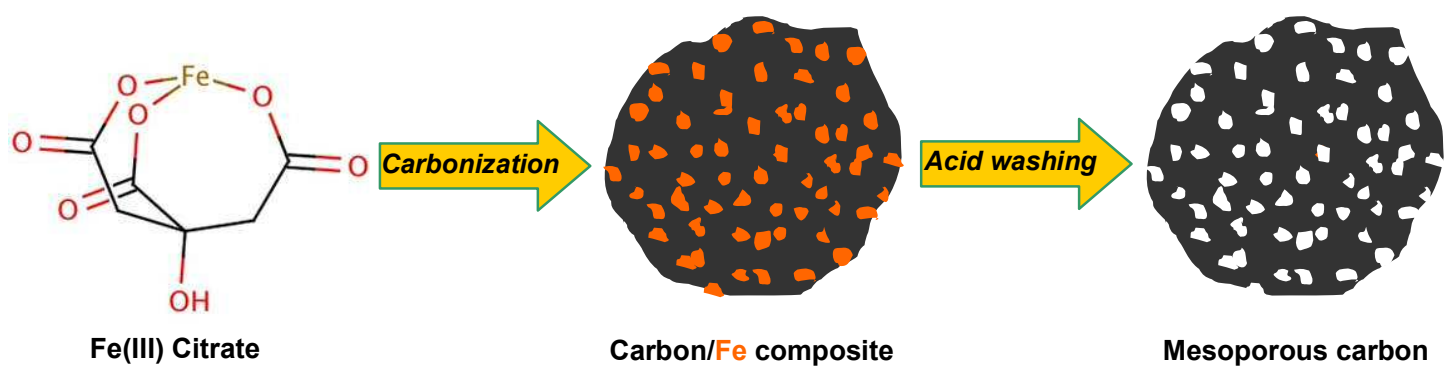

Figure 2. Schematic illustration of the synthesis procedure.

\subsection{Structural characteristics of the mesoporous carbons}

Representative SEM images of the carbons produced in this way are displayed in Figure 3. It can be seen that the carbon particles have an irregular morphology and are around $20-30 \mu \mathrm{m}$ in size. In the case of the CZn-800 sample, the carbon particles are agglomerates made up of particles of around 3 $\mu \mathrm{m}$ (see Fig. 3e). The TEM images in Figure 3 show that the carbon particles have a well-developed porosity made up of randomly oriented mesopores as can be seen from the microphotographs displayed in Figures $3 \mathrm{~b}(\mathrm{CCa}-800)$ and 3d (CFe-800). The microstructure of the mesoporous carbons was analysed using X-ray diffraction (XRD). The XRD patterns of the samples (see Figure 3d) exhibit two broad bands at around $2 \theta=24^{\circ}$ and $44^{\circ}$, which indicates that the mesoporous carbons have an amorphous structure with a low degree of graphitization.

Nitrogen physisorption measurements were carried out at $-196{ }^{\circ} \mathrm{C}$ to analyze the textural characteristics of the materials. The carbon-inorganic composites obtained by carbonization of the citrates exhibit a poor pore development, their BET surface areas being in the 64-202 $\mathrm{m}^{2} \cdot \mathrm{g}^{-1}$ range (see Table 1 and Figure 4). However, once the inorganic nanoparticles have been 
removed by acid washing, the resulting carbons exhibit a well-developed porosity as evidenced by the $\mathrm{N}_{2}$ physisorption measurements. Indeed, Figure 4 shows the $\mathrm{N}_{2}$ sorption isotherms (Figs. $4 a, 4 c$ and $4 \mathrm{e}$ ) and the pore size distributions (PSDs) (Figs. 4b, 4d and 4f) of the carbon samples obtained at a carbonization temperature of $800^{\circ} \mathrm{C}$. The isotherm profiles exhibit well-defined capillary condensation steps, which are typical of mesoporous materials (Type IV isotherm), indicating that the porosity is mainly made up of pores $>2 \mathrm{~nm}$. This is confirmed by the PSDs in Figures $4 b, 4 d$ and $4 f$, which clearly reveal that the porosity of the carbons is mainly made up of large mesopores. Interestingly, the characteristics of the pore network depend on the type of citrate salt. Thus, whereas the carbon sample from calcium citrate shows a unimodal porosity made up of large mesopores centered at around $11 \mathrm{~nm}$, the mesoporous carbons derived from iron citrate and zinc citrate exhibit a bimodal porosity formed by two mesopore systems centered at $\sim 9 \mathrm{~nm}$ and $\sim 20 \mathrm{~nm}$ for iron citrate, and at $\sim 3 \mathrm{~nm}$ and $\sim 10 \mathrm{~nm}$ for zinc citrate. The textural parameters of the synthesized carbons are listed in Table 1 . These results show that the carbon samples have large Brunauer-Emmett-Teller (BET) surface areas and pore volumes in the $950-1610 \mathrm{~m}^{2} \cdot \mathrm{g}^{-1}$ and $1.43-2.57 \mathrm{~cm}^{3} \cdot \mathrm{g}^{-1}$ ranges respectively.

The porosity of these carbons is made up almost exclusively of mesopores, as can be deduced by applying the $\alpha_{\mathrm{s}}$-plot method to the $N_{2}$ adsorption branch, where the micropores represent only $<5 \%$ of the total pore volume (see Table 1). This result shows that the physical activation (i.e. reaction between the carbon and the $\mathrm{CO}_{2}$ released during the decomposition of carbonates) or the chemical activation (i.e. chemical reactions between the inorganic compounds and carbon) processes, which typically generate 
micropores, do not play any significant role in the pore development of these materials. In other words, the porosity of these carbons is generated almost exclusively by the selective removal of the inorganic nanoparticles present in the carbon/inorganic composites. Thus, the inorganic nanoparticles which are embedded within the carbon matrix can be considered as an endotemplate material, the nanovoids left by their dissolution being the mesopores (see Figure 2). 

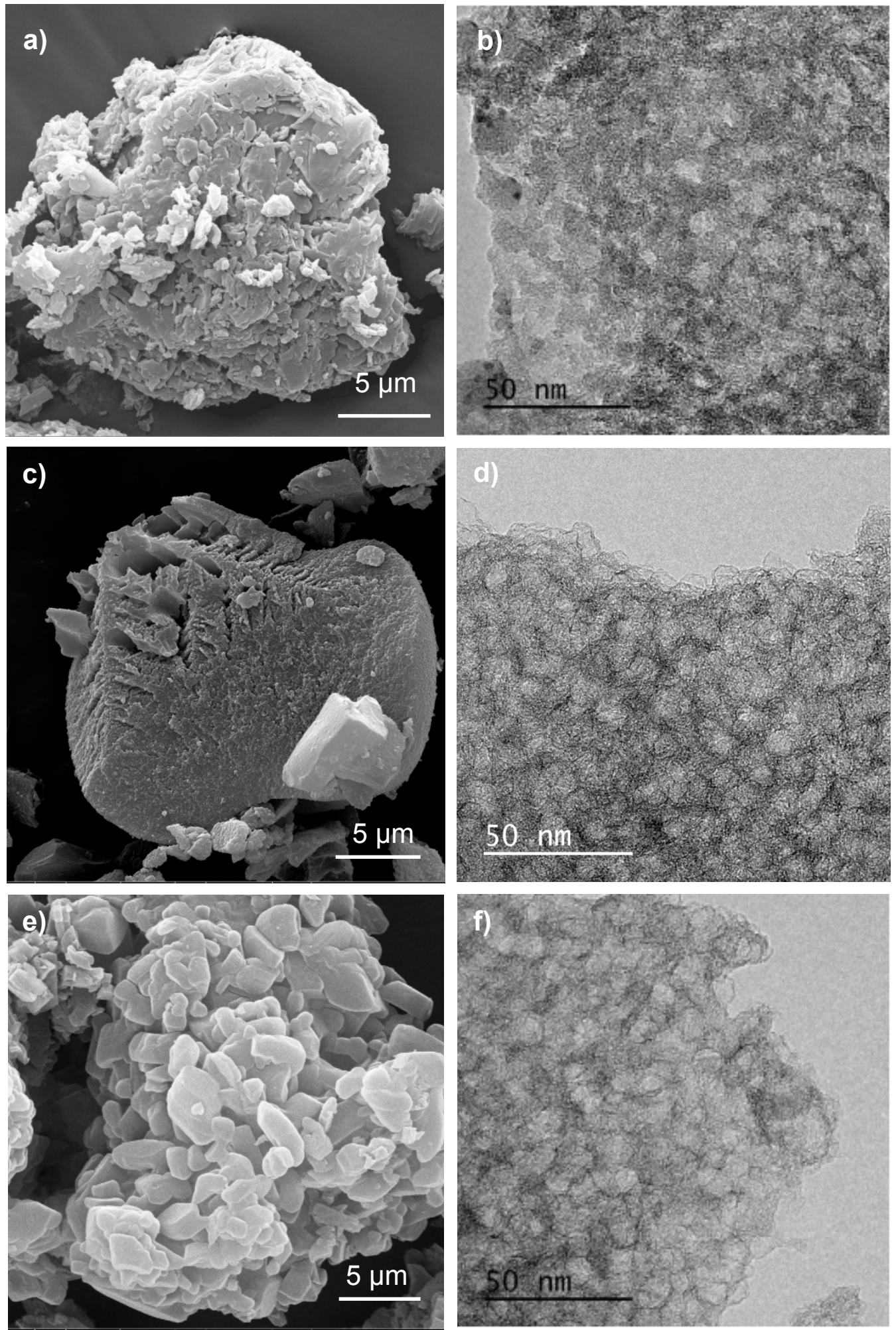

Figure 3. SEM and TEM images of the (a, b) CCa-800, (c, d) CFe-800 and (e, f) CZn-800 samples. 

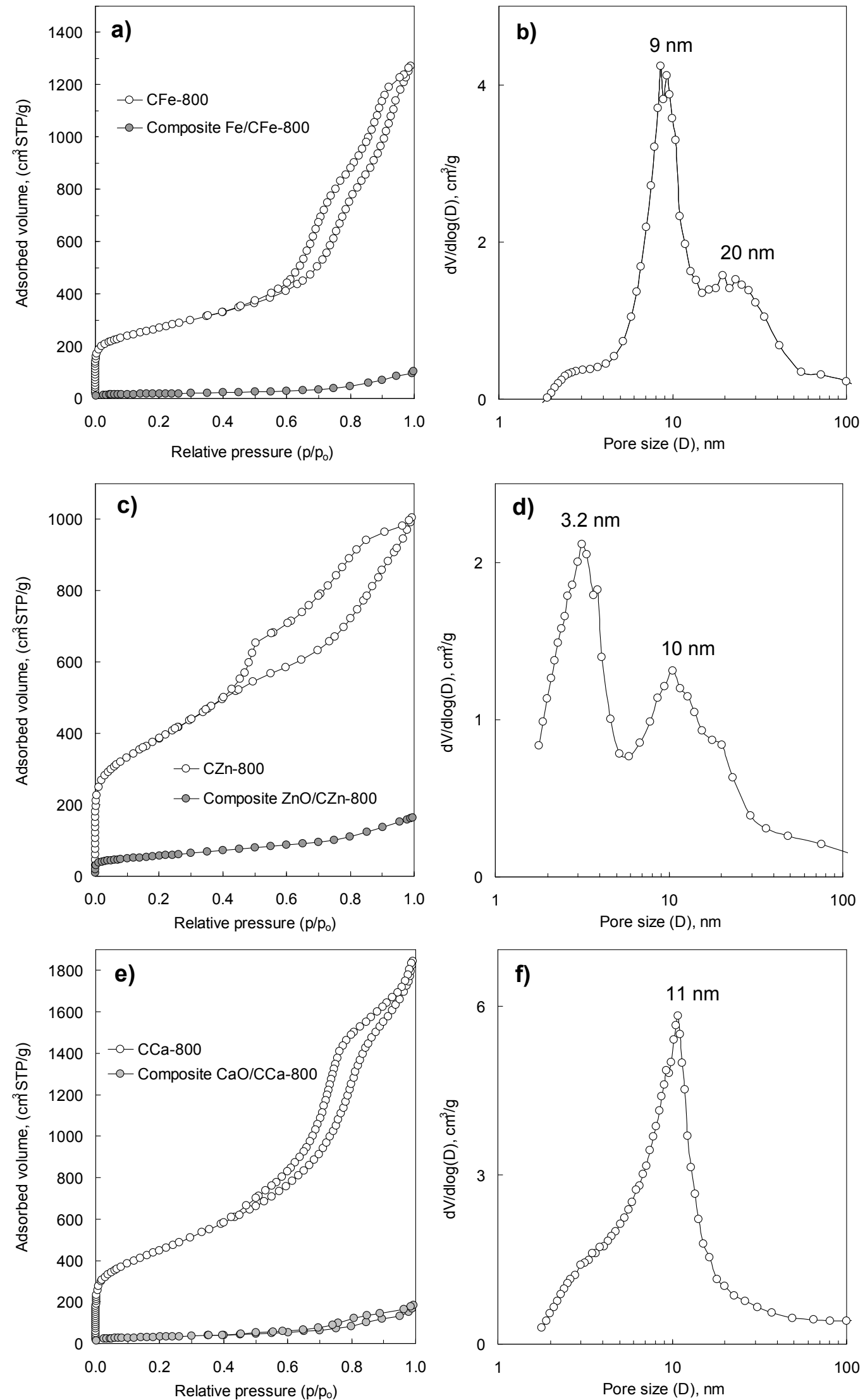

Figure 4. Nitrogen sorption isotherm ( $a, c$ and e) and pore size distributions (b, $d$ and f) of the carbon samples and their composites. 
Table 1. Textural properties of the mesoporous carbon.

\begin{tabular}{|c|c|c|c|c|}
\hline Sample Code & $S_{\text {BET }}\left(m^{2} \cdot g^{-1}\right)$ & $V_{p}\left(\mathrm{~cm}^{3} \cdot \mathrm{g}^{-1}\right)^{\mathrm{a}}$ & $V_{\text {micro }}\left(\mathrm{cm}^{3} \cdot \mathrm{g}^{-1}\right)^{b}$ & $V_{\text {meso }}\left(\mathrm{cm}^{3} \cdot \mathrm{g}^{-1}\right)^{\mathrm{c}}$ \\
\hline \multicolumn{5}{|c|}{ Carbon/Inorganic composites } \\
\hline Carbon/Fe & 64 & 0.16 & - & - \\
\hline Carbon/ZnO & 202 & 0.25 & - & 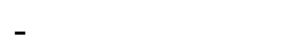 \\
\hline Carbon/CaO & 112 & 0.29 & - & - \\
\hline \multicolumn{5}{|c|}{ Mesoporous carbons } \\
\hline CFe-800 & 950 & 1.83 & 0.07 & 1.76 \\
\hline CZn-800 & 1380 & 1.43 & 0.09 & 1.34 \\
\hline CCa- 800 & 1610 & 2.57 & 0.04 & 2.53 \\
\hline \multicolumn{5}{|c|}{$\mathrm{N}$-doped mesoporous carbons } \\
\hline CZn-800-N & 1190 & 1.20 & 0.10 & 1.10 \\
\hline CCa-800-N & 1350 & 1.79 & 0.06 & 1.73 \\
\hline
\end{tabular}

${ }^{\mathrm{a}}$ Pore volume at $\mathrm{p} / \mathrm{p}_{\mathrm{o}} \sim 0.95 .{ }^{\mathrm{b}}$ Micropore volume was determined by using the $\alpha_{\mathrm{s}}$-plot method applied to the $\mathrm{N}_{2}$ adsorption branch. ${ }^{\circ}$ Mesopore volume obtained by the difference between pore volume $\left(V_{p}\right)$ and micropore volume $\left(V_{\text {micro }}\right)$.

\subsubsection{N-doped mesoporous carbons}

The $\mathrm{N}$-doped mesoporous carbons were synthesized by the heat treatment of a mixture of mesoporous carbon and melamine at $800^{\circ} \mathrm{C}$. In a first stage, at temperatures $<500{ }^{\circ} \mathrm{C}$, the polymerization of the melamine takes place, giving rise to a carbon nitride allotrope $\left(g-C_{3} N_{4}\right)$. Subsequently, at higher temperatures, this compound completely decomposes into numerous nitrogencontaining species (e.g. $\mathrm{C}_{2} \mathrm{~N}_{2}{ }^{+}, \mathrm{C}_{3} \mathrm{~N}_{2}{ }^{+}, \mathrm{C}_{3} \mathrm{~N}_{3}{ }^{+}$, etc) that react with the mesoporous carbon, resulting in the incorporation of numerous nitrogen functional groups into the carbon framework [25]. At this point, we want to indicate that we found in a previous work that the co-carbonization of a mixture of melamine and a citrate salt gives rise to a $\mathrm{N}$-doped carbon with a porosity made up almost exclusively by micropores, suggesting thereby that the presence of melamine prevents the formation of a mesoporous network [25]. Therefore, as shown in the present work, an additional step with melamine is required for the incorporation of $\mathrm{N}$-groups into mesoporous carbons. 
The $\mathrm{N}$-doped mesoporous carbons obtained in this way have large nitrogen contents of $8.54 \mathrm{wt} \%$ and $9.23 \mathrm{wt} \%$ for the CZn-800-N and CCa-800$\mathrm{N}$ samples respectively, as can be deduced from the elemental chemical analysis data (see Table 2). To evaluate the nature of the nitrogen functional groups present in the N-doped carbons, XPS measurements were carried out (see Figure 5). The high-resolution $\mathrm{N}$ 1s XPS spectrum for the CZn-800-N sample can be deconvoluted in two main peaks at $398.4 \mathrm{eV}$ and $400.4 \mathrm{eV}$. These are assigned to pyridinic-N (57.4 \%) and pyrrolic-N (33.8\%) respectively, whereas two minor peaks at $401.8 \mathrm{eV}$ and $403.3 \mathrm{eV}$ are attributed respectively to quaternary- $\mathrm{N}(3.9 \%)$ and pyridine-N-oxides (4.8\%). Similarly, two main contributions were found in CCa-800-N sample, which are assigned to pyridinic$\mathrm{N}(58.8 \%)$ and pyrrolic-N (28.5\%), and a small peak at $401.3 \mathrm{eV}$, which is attributed to quaternary-N (12.7\%) (see Table 2) [26, 27].

Table 2. Chemical composition and distribution of the nitrogen functional groups.

\begin{tabular}{|c|c|c|c|c|c|c|c|c|}
\hline \multirow[t]{2}{*}{ Sample code } & \multicolumn{4}{|c|}{ Composition (wt \%) } & \multicolumn{4}{|c|}{ Nitrogen functional groups (\%) } \\
\hline & $\mathrm{C}$ & $\mathrm{H}$ & $\mathrm{N}$ & $\mathrm{O}$ & $\mathrm{N}-5^{\mathrm{a}}$ & $\mathrm{N}-6^{\mathrm{b}}$ & $\mathrm{N}-\mathrm{Q}^{\mathrm{C}}$ & $\mathrm{N}-\mathrm{O}^{\mathrm{d}}$ \\
\hline CFe-800 & 82.2 & 1.96 & 0.46 & 15.4 & - & - & - & - \\
\hline CZn-800 & 89.5 & 0.78 & 0.25 & 9.5 & - & - & - & - \\
\hline CCa-800 & 87.0 & 0.88 & 0.24 & 11.8 & - & - & - & - \\
\hline CZn-800-N & 82.2 & 0.42 & 8.54 & 8.84 & 33.8 & 57.4 & 3.9 & 4.8 \\
\hline CCa-800-N & 79.4 & 0.44 & 9.23 & 10.93 & 28.5 & 58.8 & 12.7 & - \\
\hline
\end{tabular}




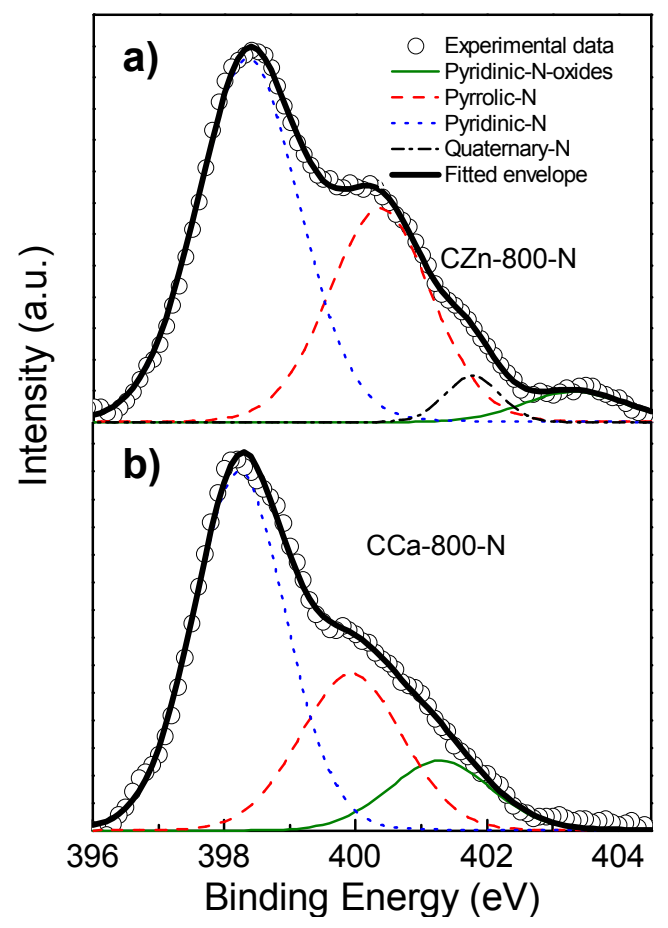

Figure 5. High-resolution XPS N 1s core level spectra of (a) CZn-800-N and (b) CCa-800-N.

After the incorporation of the nitrogen functional groups, there is a decrease in the surface area and pore volume. However, the N-doped carbons still exhibit high BET surface areas $\left(1190 \mathrm{~m}^{2} \cdot \mathrm{g}^{-1}\right.$ for CZn-800-N and $1350 \mathrm{~m}^{2} \cdot \mathrm{g}^{-1}$ for CCa-800-N) and large pore volumes, as shown in Table 1. Interestingly, these doped samples retain the mesoporous structure, as can be inferred from the nitrogen sorption isotherms and pore size distributions in Figure S2. These results reveal that these $\mathrm{N}$-carbons have a porosity made up of large mesopores similar to that observed in the undoped samples.

The combination of an open mesostructure together with a large number of nitrogen functional groups is important for the use of these materials as highperformance supercapacitor electrodes in an aqueous electrolyte (e.g. $\mathrm{H}_{2} \mathrm{SO}_{4}$ ). Indeed, while the large mesopores facilitate the transport and diffusion of electrolyte ions during the fast charge/discharge processes, the $\mathrm{N}$-groups 
enhance capacitance due to the pseudo-capacitive effects contributed by these nitrogen functionalities.

\subsection{Electrochemical performance of the mesoporous carbons}

\subsubsection{Aqueous electrolyte: $1 \mathrm{M} \mathrm{H}_{2} \mathrm{SO}_{4}$}

Electrochemical impedance spectroscopy (EIS) experiments were carried out to evaluate the effectiveness of the charge transport within the pore structure of undoped (CCa-800) and N-doped (CCa-800-N) mesoporous carbons in $1 \mathrm{M} \mathrm{H}_{2} \mathrm{SO}_{4}$ electrolyte. The Nyquist plots in Figure 6a exhibit at low frequencies an almost vertical line, parallel to the imaginary axis, indicating that the behavior of the supercapacitors is close to that of an ideal capacitor. The high-frequency intersection of the plot with the X-axis represents the equivalent series resistance (ESR), which is associated with the resistance of the material, the separator and the contact between the materials and the current collector $[28,29]$. As can be seen, this $E S R$ is $\sim 0.20 \Omega$ in the case of the $N$-doped carbon, which is lower than that of the undoped sample $(\sim 0.29 \Omega)$. The lower value obtained for the CCa-800-N sample can be ascribed to its superior electronic conductivity $\left(0.87 \mathrm{~S} \mathrm{~cm}^{-1}\right)$ compared to the undoped carbon CCa-800 $\left(0.26 \mathrm{~S} \mathrm{~cm}^{-1}\right)$. The Warburg region is almost negligible in the intermediate frequency region, which indicates that the electrolyte ions can easily move through the mesoporous channels, contributing to a rapid electrochemical process. From the results represented in Figure $6 \mathrm{~b}$, it can be deduced that both mesoporous carbons possess small relaxation time constants in the $0.27-0.37 \mathrm{~s}$ range in $\mathrm{H}_{2} \mathrm{SO}_{4}$ electrolyte, indicating that the electrodes possess a good rate performance owing to their accessible pore structure. These values are lower than those reported for many porous carbons such as, meso- and microporous 
carbon materials (18 s) [30], and three-dimensionally hierarchical porous carbon (6.7 s) [31] but similar to those of rich nitrogen-doped ordered mesoporous carbons $(\sim 0.36 \mathrm{~s})[32]$.
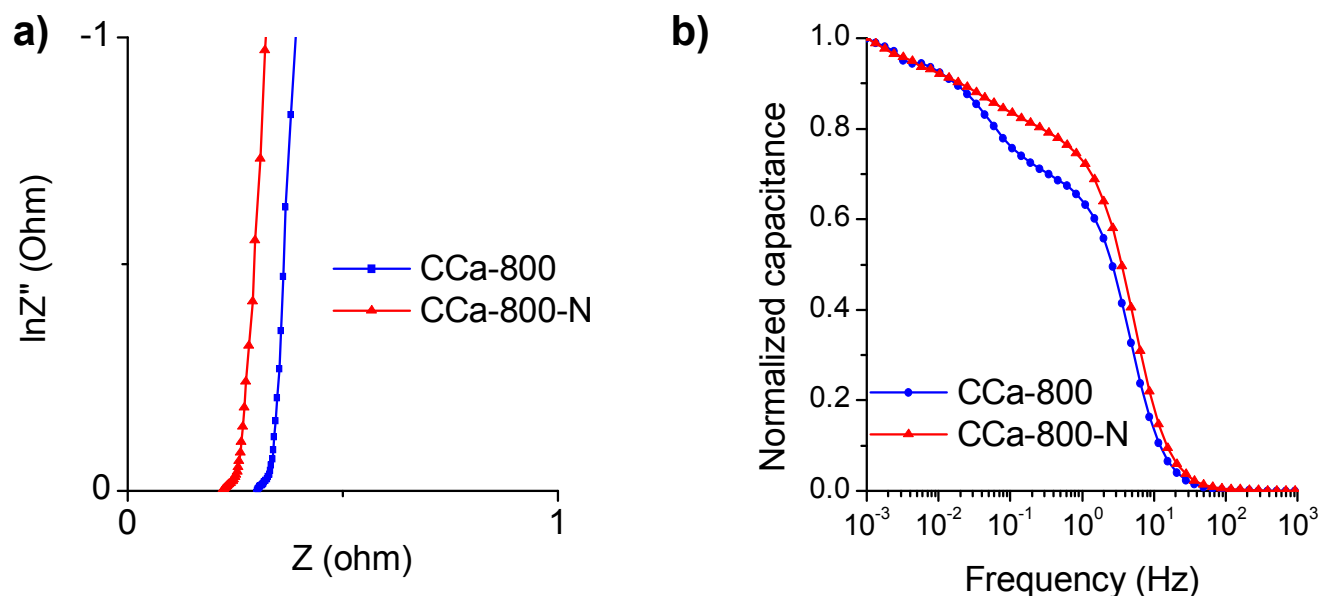

Figure 6. a) Nyquist plots and b) frequency response for the mesoporous carbon samples in $1 \mathrm{M} \mathrm{H}_{2} \mathrm{SO}_{4}$ electrolyte.

A special two-electrode cell provided with a reference electrode was used to investigate pseudocapacitance effects associated with the nitrogen/oxygen-containing functional groups in the individual electrodes and also to determine the maximum voltage stability window. Figure $7 a-7 b$ shows the corresponding cyclic voltammograms obtained at a sweep rate of $5 \mathrm{mV} \mathrm{s}^{-1}$ for each single electrode, both positive and negative. A well-defined peak is visible for the positive electrode of both materials at $-0.1 \mathrm{~V}(\mathrm{vs}$. Hg/SME) during positive polarization and at $-0.2 \mathrm{~V}(\mathrm{vs}$. $\mathrm{Hg} / \mathrm{SME})$ during negative polarization. This peak can be assigned to redox reactions involving the quinone/hydroquinone pair [33-35]. However, the intensity is higher in the case of the undoped sample (CCa-800) owing to its higher oxygen content (see Table 2) and therefore the specific capacitance for the positive electrode is higher (183 $\mathrm{F} \mathrm{g}^{-1}$ vs. $145 \mathrm{~F} \mathrm{~g}^{-1}$ for the $\mathrm{N}$-doped carbon). On the contrary, in the 
case of the negative electrode, the $\mathrm{N}$-doped mesoporous carbon achieves a higher specific capacitance $\left(188 \mathrm{~F} \mathrm{~g} \mathrm{~g}^{-1}\right)$ than the undoped carbon sample (178 $\mathrm{F}$ $\mathrm{g}^{-1}$ ). This is especially evident when the surface area-normalized capacitance $\left(\mathrm{C}_{\mathrm{s}}\right)$ of the negative electrode is evaluated. Thus, the CCa-800-N possesses a $\mathrm{C}_{\mathrm{s}} \sim 14 \mu \mathrm{F} \mathrm{cm}{ }^{-2}$, which is higher than that of the undoped material (i.e. $\mathrm{C}_{\mathrm{s}} \sim 11$ $\mu \mathrm{F} \mathrm{cm}^{-2}$ ). This is consequence of the broad hump observed for the negative electrode of CCa-800-N, which can be ascribed to redox reactions involving the pyridinic/pyrrolic groups (see Figure 5) and electrolyte protons [36, 37]. Furthermore, it is worth noting that the incorporation of nitrogen functionalities allows the operating voltage window to be enlarged from $1.1 \mathrm{~V}$ for the $\mathrm{CCa}-800$ sample to $1.2 \mathrm{~V}$ for the CCa-800-N sample. 
a)

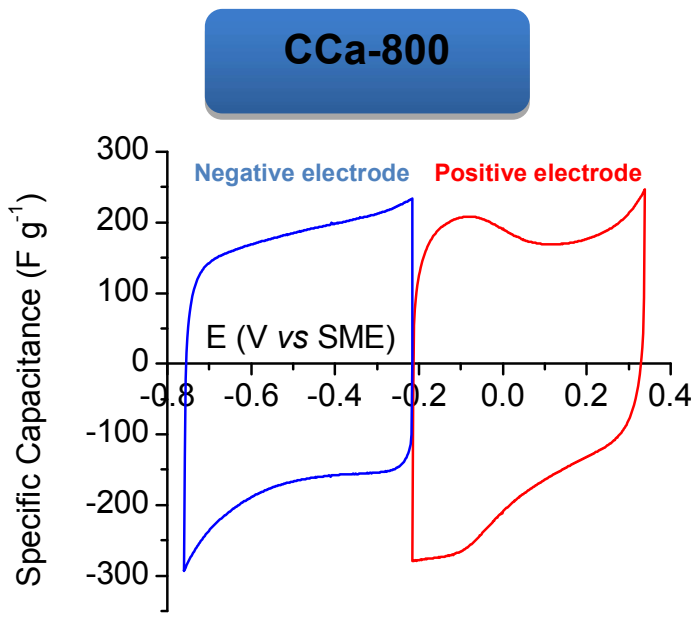

c)

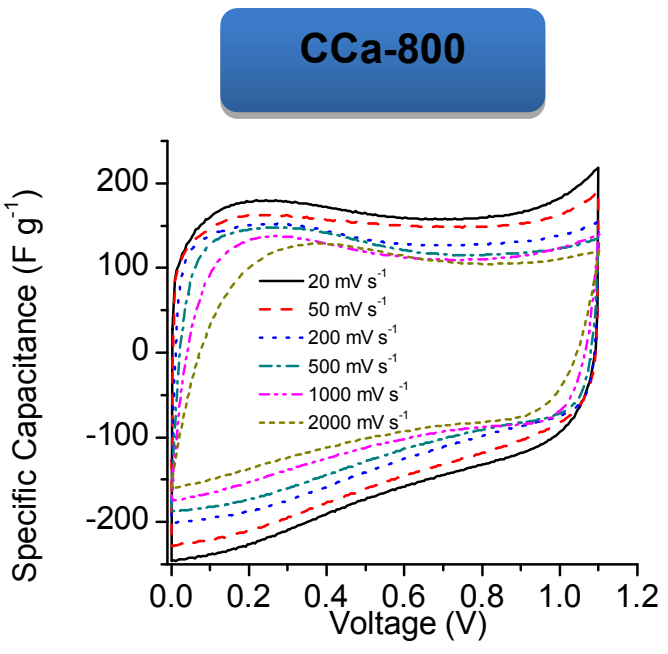

b)

CCa-800-N

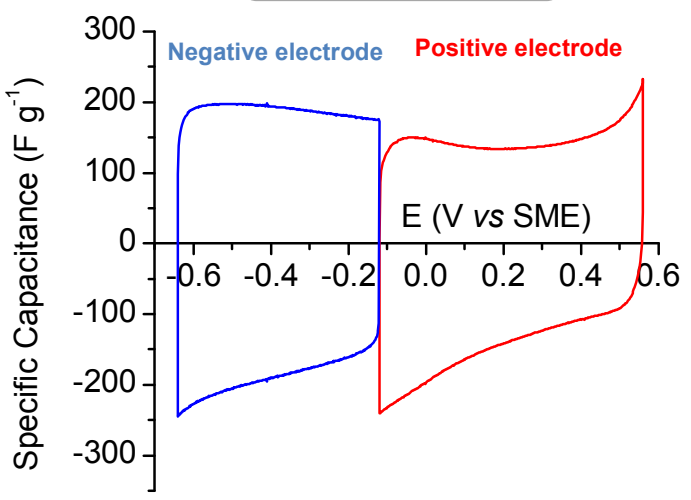

d)

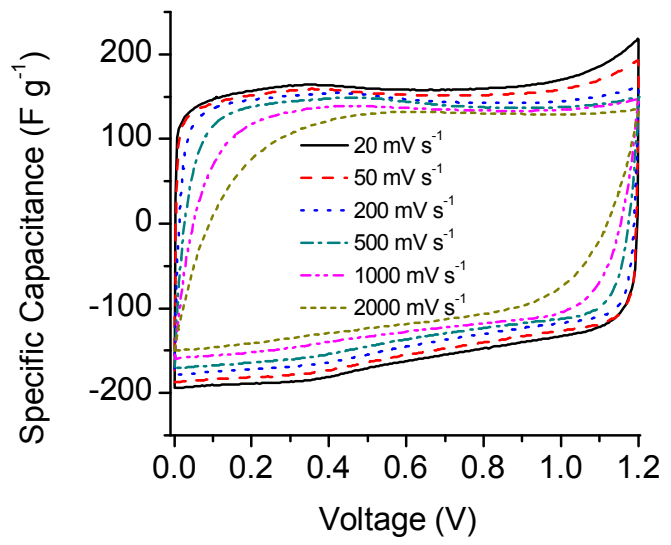

Figure 7. Cyclic voltammograms at $5 \mathrm{mV} \mathrm{s}^{-1}$ for positive and negative electrode in a special two-electrode cell configuration for (a) CCa-800 and (b) CCa-800-N and cyclic voltammograms in a two-electrode cell configuration at different scan rates for (c) CCa-800 and (d) CCa-800-N, in $1 \mathrm{M} \mathrm{H}_{2} \mathrm{SO}_{4}$ electrolyte.

The electrochemical behavior of the mesoporous carbon materials was also examined by means of cyclic voltammetry (CV) experiments in a conventional two-electrode configuration, as illustrated in Figure $7 c-7 d$. The cyclic voltammograms exhibit a quasi-rectangular shape even up to $2 \mathrm{~V} \mathrm{~s}^{-1}$, indicating fast ion and electron transport throughout the mesoporous network, in contrast to the commercial activated carbon Supra DLC-50, which exhibits 
restricted charge propagation even at $500 \mathrm{mV} \mathrm{s}^{-1}$ (see Figure S3). The more pronounced hump observed in the CVs of the CCa-800 sample with respect to CCa-800-N agrees well with the results obtained with the special 2-electrode cell.

Galvanostatic Charge-Discharge (CD) experiments were performed to evaluate the capacitive performance of the carbon materials. The CD profiles obtained at different current densities are shown in Figures S4a-c. Both the undoped and $\mathrm{N}$-doped samples exhibit a small IR drop at ultra-high current densities as high as $120 \mathrm{~A} \mathrm{~g} \mathrm{~g}^{-1}$ (coulombic efficiency $\sim 98-99 \%$ ). This remarkable capacitive behavior is mainly due to the fact that the porosity is made up of wide mesopores that facilitate the transport and diffusion of the electrolyte ions even at high current densities. This excellent rate performance at high discharge current densities is confirmed by the results in Figure 8a, which show the variation in specific capacitance with increasing current density. Thus, the CCa-800 sample possesses a specific capacitance of $243 \mathrm{~F} \mathrm{~g}^{-1}$ at a low current density of $0.1 \mathrm{~A} \mathrm{~g}^{-1}$, which is superior to that of the $\mathrm{N}$-doped carbon sample $\left(208 \mathrm{~F} \mathrm{~g}^{-1}\right)$. Significantly, at an ultra-high current density such as $150 \mathrm{~A}$ $\mathrm{g}^{-1}$ the CCa-800-N sample still retains a specific capacitance of $138 \mathrm{~F} \mathrm{~g}^{-1}(66 \%)$, while the CCa-800 sample possesses a capacitance retention of $44 \%$ (see Figure S4d). On the opposite side, the activated carbon Supra cannot work at discharge rates higher than $40 \mathrm{~A} \mathrm{~g}^{-1}$ (see Figure 8a) owing to the much higher ESR resistance (see Figure S4b).The high rate capability offered by CCa-800-N is comparable to, or superior than, that of other nitrogen-doped carbon materials found in the literature, such as ordered mesoporous carbons (53 \% at $20 \mathrm{~A} \mathrm{~g}^{-1}$ in $\mathrm{H}_{2} \mathrm{SO}_{4} 1 \mathrm{M}$ ) [32], carbon nanospheres (63\% at $20 \mathrm{~A} \mathrm{~g}^{-1}$ in $\mathrm{KOH} 6 \mathrm{M}$ ) 
[38], activated carbon materials (65 \% at $20 \mathrm{~A} \mathrm{~g}^{-1}$ in $\mathrm{KOH} 7 \mathrm{M}$ ) [39], hierarchical meso/microporous carbon materials (54\% at $20 \mathrm{~A} \mathrm{~g}^{-1}$ in $\left.\mathrm{H}_{2} \mathrm{SO}_{4} 1 \mathrm{M}\right)$ [40] and mesoporous carbon nanosheets ( $82 \%$ at $8 \mathrm{~A} \mathrm{~g}^{-1}$ in $\mathrm{H}_{2} \mathrm{SO}_{4} 1 \mathrm{M}$ ) [29]. This better rate capability of the $\mathrm{N}$-doped sample can be attributed to its superior electrical conductivity, the better surface wettability by the electrolyte due to the incorporation of nitrogen species [41, 42], and probably faster redox reactions, as evidenced by the higher surface area-normalized capacitance over the whole range of discharge rates (see Figure S5a).

a)

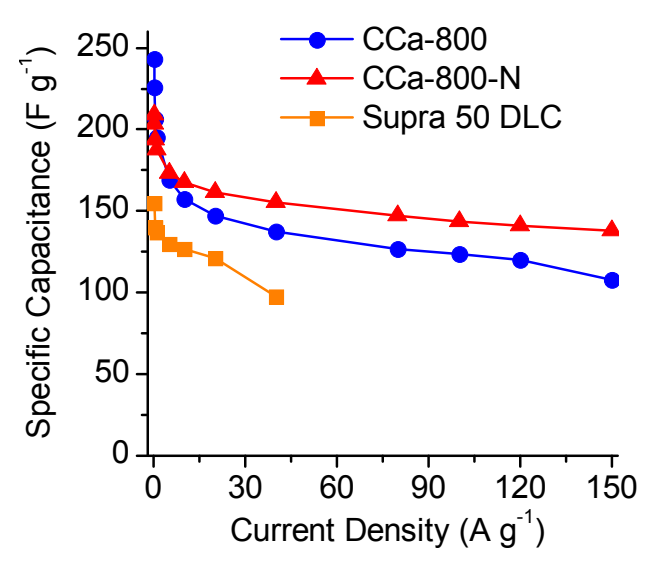

b)

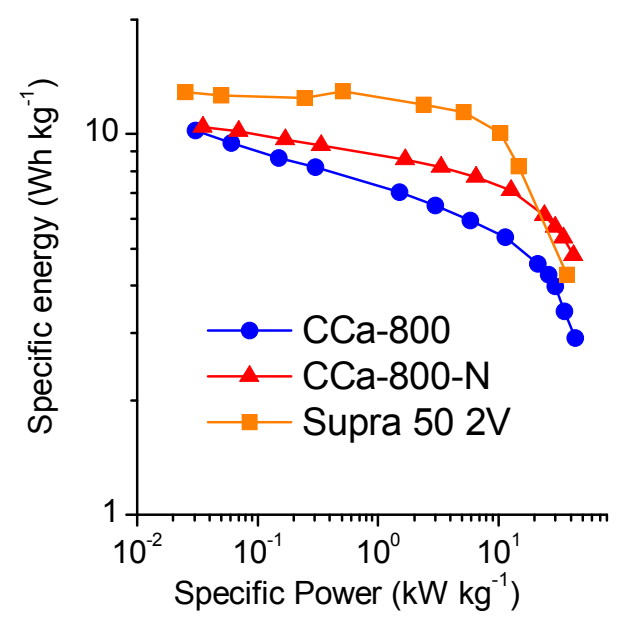

Figure 8. (a) Variation of specific capacitance with increasing discharge current density and (b) Ragone plot of the mesoporous materials (data for the commercial activated carbon Supra DLC-50 in $\mathrm{H}_{2} \mathrm{SO}_{4}$ and $\mathrm{TEABF}_{4} / \mathrm{AN}$ are included for comparison in Figures a and $\mathrm{b}$ respectively). Electrolyte: $1 \mathrm{M}$ $\mathrm{H}_{2} \mathrm{SO}_{4}$.

The energy and power characteristics of the mesoporous carbon samples are compared in a Ragone-like plot (Figure 8b). The maximum amount of energy stored by the CCa-800-N-based supercapacitor is $\sim 10 \mathrm{Wh} \mathrm{kg}^{-1}$ (35 W $\left.\mathrm{kg}^{-1}\right)$ and the maximum specific power is $48 \mathrm{~kW} \mathrm{~kg}^{-1}\left(4.8 \mathrm{Wh} \mathrm{kg}^{-1}\right)$. Similar 
values of specific energy are obtained for the undoped carbon sample at the lowest discharge rate. However, for higher discharge rates, the energy stored by CCa-800-N is greater than that of CCa-800, irrespective of the specific power value owing to its better rate capability. In addition, Figure 8b compares the energy and power characteristics of the synthesized materials with those of the commercial Supra DLC-50 in organic electrolyte $\left(\mathrm{TEABF}_{4} / \mathrm{AN}\right)$. In spite of the lower cell voltage in the case of $\mathrm{CCa}-800$ and $\mathrm{CCa}-800-\mathrm{N}$, their specific energy is higher than that of Supra 50 for specific powers higher than $10 \mathrm{~kW} \mathrm{~kg}^{-}$

${ }^{1}$, highlighting the superiority of these materials for high-power applications.

The stability of the electrode materials under long-term cycling was analyzed over 10000 cycles by applying a discharge current density of $5 \mathrm{~A} \mathrm{~g}^{-1}$ at the maximum operating cell voltage (Figure S5b). The results reveal an outstanding capacitance retention of $98 \%$ for CCa-800-N sample and $94 \%$ for the CCa-800 sample, suggesting that no deterioration takes place despite the large cell voltage. This is corroborated by the superimposition of the $1^{\text {st }}$ and $10000^{\text {th }}$ charge/discharge cycle and CV in Figures S5c and S5d respectively.

The above results evidence that $\mathrm{N}$-doping is beneficial for i) enhancing rate capability as a result of a higher electronic conductivity and improved surface wettability, and ii) enhancing the electrochemical stability of the system as a consequence of a greater resistance to oxidation.

\subsubsection{Ionic Liquid Electrolyte: EMImTFSI/AN}

As the carbon samples have a porosity made up of large mesopores, they can be expected to show a good electrochemical performance with bulky electrolytes such as ionic liquids (ILs). To determine this, we examined the electrochemical energy storage performance of the mesoporous carbons using 
the IL EMImTFSI mixed with acetonitrile (AN) as electrolyte. We employed an imidazolium-based IL because of its relatively higher ionic conductivity compared to other types of IL [43]. It was, however, mixed with acetonitrile to reduce its viscosity. Figures $9 a-9 b$ show the $\mathrm{CVs}$ at different scan rates. The box shape reveals that the charge storage mechanism is mainly based on the formation of an electric double-layer. This box shape is maintained even at high scan rates of $1 \mathrm{~V} \mathrm{~s}^{-1}$ owing to the mesoporous structure that provides fast iontransport rates, in contrast to the distorted voltammogram exhibited by the activated carbon Supra DLC-50 (see Figure S6a). The specific capacitance of the CCa-800-based capacitor was $130 \mathrm{~F} \mathrm{~g}^{-1}$ at a low scan rate $\left(2 \mathrm{mV} \mathrm{s}^{-1}\right)$, which is superior to that of the $\mathrm{N}$-doped carbon $\left(101 \mathrm{~F} \mathrm{~g}^{-1}\right)$, which has a lower specific surface area. Confirmation of the good rate capability of the mesoporous carbons was provided by the galvanostatic charge-discharge cycling experiments. Thus, as can be seen in Figure 9c, the mesoporous-based supercapacitors retain $>80 \%$ of the initial capacitance at a high discharge rate of $100 \mathrm{~A} \mathrm{~g}^{-1}$, whereas capacitance retention of Supra DLC-50 is $70 \%$ at its highest operating discharge rate, i.e. $60 \mathrm{~A} \mathrm{~g} \mathrm{~g}^{-1}$. The high rate capability performance of these mesoporous carbon materials is comparable to that of other advanced carbon materials found in the literature, such as hierarchical carbon (84\% at $50 \mathrm{~A} \mathrm{~g}^{-1}$ in EMImTFSI) [44], graphene sheets (75\% at $4 \mathrm{~A} \mathrm{~g}^{-1}$ in $\mathrm{EMImBF}_{4}$ ) [45], three-dimensional graphitized carbon nanovesicles (66 \% at 9.6 $\mathrm{A} \mathrm{g}^{-1}$ in $\left.\mathrm{EMIBF}_{4}\right)$ [46] or activated carbon fiber cloths $\left(20 \%\right.$ at $50 \mathrm{~mA} \mathrm{~cm}{ }^{-2}$ in EMI-FSI) [47].

The specific energy and power data collected from the galvanostatic charge-discharge experiments were represented in a Ragone-like plot (Figure 
9d). The CCa-800 sample exhibits the highest value of energy stored ( $33 \mathrm{Wh}$ $\mathrm{kg}^{-1}$ ) at a specific power density of $\sim 14 \mathrm{~kW} \mathrm{~kg}^{-1}$, compared to $\sim 26 \mathrm{Wh} \mathrm{kg}^{-1}$ in the case of the CCa-800-N sample. The maximum energy stored by the CCa800 sample is $\sim 41 \mathrm{Wh} \mathrm{kg}^{-1}$ and the maximum specific power is $66.6 \mathrm{~kW} \mathrm{~kg}^{-1}$. Compared to the results obtained in $\mathrm{H}_{2} \mathrm{SO}_{4}$, a 4-fold increase was recorded for the specific energy, so that the higher cell voltage compensates for the much lower specific capacitance.
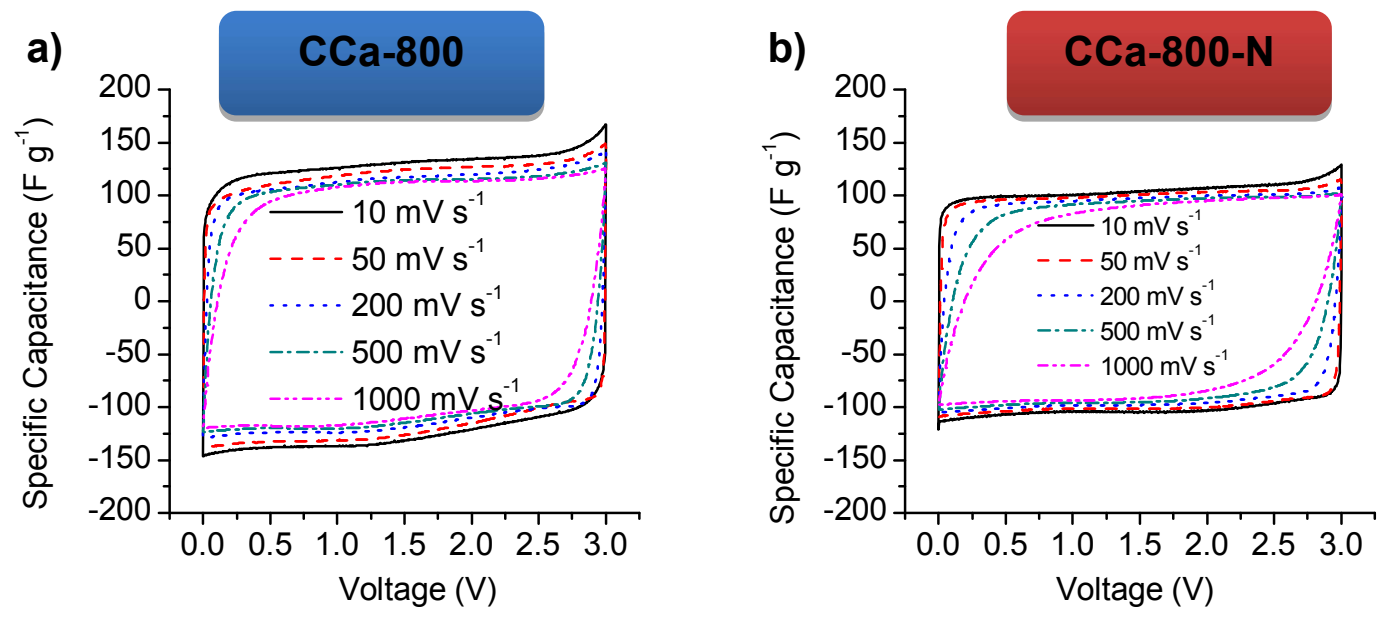

c)
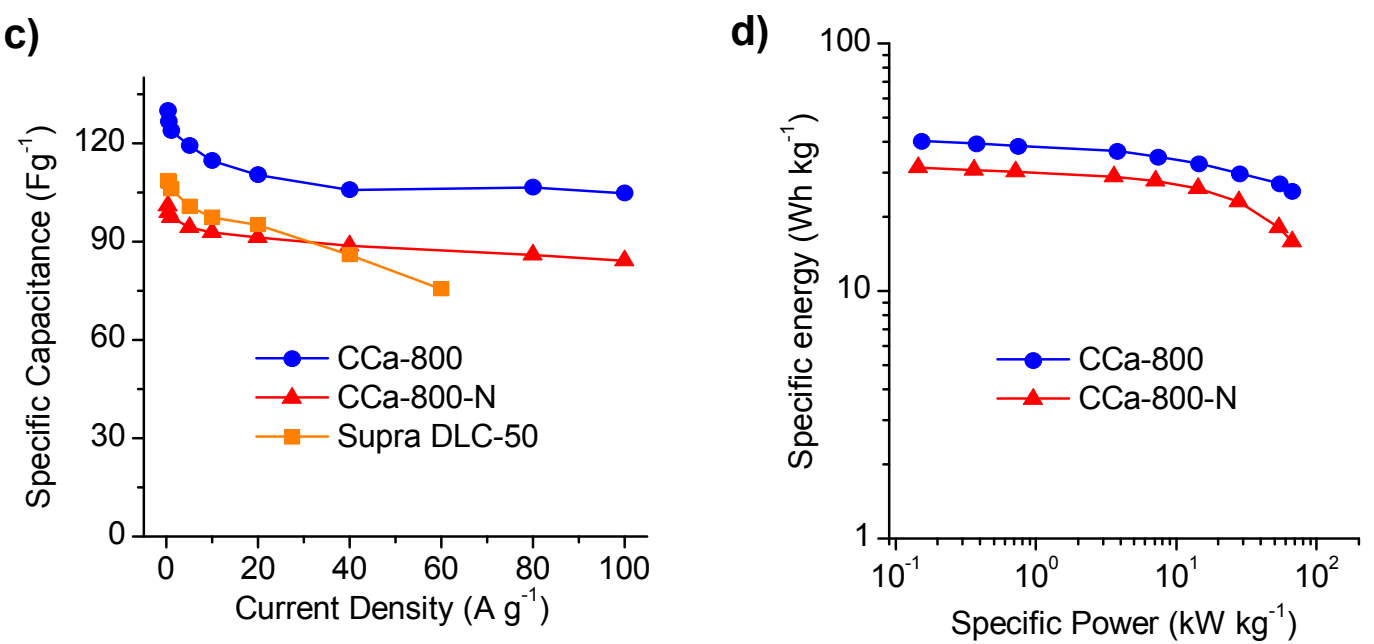

Figure 9. Cyclic voltammograms at different scan rates for (a) CCa-800 and (b) CCa-800-N, (c) variation of the specific capacitance with increasing current density and (d) Ragone plot for the mesoporous carbon materials. Electrolyte: EMImTFSI/AN. (Data for the commercial activated carbon Supra DLC-50 are included in Figure $\mathrm{c}$ for comparison). 
Long-term cycling tests were performed to evaluate the cycle durability of the synthesized materials. As shown in Figure S6b, the CCa-800-N sample shows a remarkable capacitance retention of $96 \%$ over 5000 cycles at a large discharge rate of $10 \mathrm{~A} \mathrm{~g}^{-1}$, whereas sample CCa-800 shows a reasonable capacitance retention of $88 \%$, reflecting the good stability of these mesoporous materials.

\section{Conclusions}

In summary, we have described a novel and facile one-step procedure to fabricate mesoporous carbons consisting in the direct carbonization of citrate salts of iron, zinc or calcium. The carbonized materials obtained in this way consist of a carbonaceous matrix that contains numerous uniformly distributed inorganic nanoparticles of $\mathrm{Fe}, \mathrm{ZnO}$ or $\mathrm{CaO}$. The removal of these nanoparticles give rise to carbons with a large BET surface area $\left(950-1610 \mathrm{~m}^{2} \mathrm{~g}^{-1}\right)$ and a porosity made up almost exclusively of mesopores. The size of these mesopores depends on the type of citrate salt selected. Furthermore, it has been shown that by means of an additional heat-treatment step in the presence of melamine it is possible to incorporate a large number of nitrogen functional groups $(\sim 8-9$ wt $\%)$ into these carbon samples without damaging their textural properties. The mesoporous carbon materials were tested as electrode materials in supercapacitors in aqueous $\left(1 \mathrm{M} \mathrm{H}_{2} \mathrm{SO}_{4}\right)$ and ionic liquid electrolyte (EMImTFSI/AN). Good specific capacitances of $200-240 \mathrm{~F} \mathrm{~g}^{-1}$ in $1 \mathrm{M} \mathrm{H}_{2} \mathrm{SO}_{4}$ and 100-130 $\mathrm{F} \mathrm{g}^{-1}$ in EMImTFSI/AN were achieved for the mesoporous carbons. The incorporation of nitrogen groups provided a larger voltage stability window (1.2 V) in $1 \mathrm{M} \mathrm{H}_{2} \mathrm{SO}_{4}$, and led to a better rate performance (66\% at an ultra- 
high current density of $150 \mathrm{~A} \mathrm{~g} \mathrm{~g}^{-1}$ ) due to a superior electronic conductivity, a better surface wettability and faster redox reactions than in the case of the undoped carbon in aqueous electrolyte. The mesoporous structure facilitated the transport and diffusion of bulky electrolyte ions such as those found in ionic liquids, giving rise to a good capacitance retention at ultra-high rates (up to 150 $\mathrm{A} \mathrm{g}^{-1}$ in $\mathrm{H}_{2} \mathrm{SO}_{4}$ and $100 \mathrm{~A} \mathrm{~g}^{-1}$ in EMImTFSI/AN).

Acknowledgments. This research work was supported by the Spanish Ministerio de Economía y Competitividad, MINECO (MAT2012-31651), and Fondo Europeo de Desarrollo Regional (FEDER). G. A. F. thanks the MINECO for his predoctoral contract and M. S. thanks the Ministerio de Ciencia e Innovación of Spain for her Ramón y Cajal contract.

\section{References}

[1] Simon P, Gogotsi Y. Capacitive Energy Storage in Nanostructured Carbon-Electrolyte Systems. Acc Chem Res. 2012;46(5):1094-103.

[2] Beguin F, Presser V, Balducci A, Frackowiak E. Supercapacitors: carbons and electrolytes for advanced supercapacitors. Adv Mater. $2014 ; 26(14): 2283$.

[3] Choi N-S, Chen Z, Freunberger SA, Ji X, Sun Y-K, Amine K, et al. Challenges Facing Lithium Batteries and Electrical Double-Layer Capacitors. Angew Chem Int Ed. 2012;51(40):9994-10024.

[4] Sevilla M, Fuertes AB, Mokaya R. High density hydrogen storage in superactivated carbons from hydrothermally carbonized renewable organic materials. Energy Environ Sci. 2011;4(4):1400-10. 
[5] Apul OG, Karanfil T. Adsorption of synthetic organic contaminants by carbon nanotubes: A critical review. Water Research. 2015;68:34-55.

[6] Ikeda S, Ishino S, Harada T, Okamoto N, Sakata T, Mori H, et al. LigandFree Platinum Nanoparticles Encapsulated in a Hollow Porous Carbon Shell as a Highly Active Heterogeneous Hydrogenation Catalyst. Angew Chem Int Ed. 2006;45(42):7063-6.

[7] Sevilla M, Mokaya R. Energy storage applications of activated carbons: supercapacitors and hydrogen storage. Energy Environ Sci. 2014;7(4):1250-80. [8] McEnaney B. Properties of Activated Carbons. Handbook of Porous Solids: Wiley-VCH Verlag GmbH 2008, p. 1828-63.

[9] Oya A, Kasahara N. Preparation of thin carbon fibers from phenolformaldehyde polymer micro-beads dispersed in polyethylene matrix. Carbon. $2000 ; 38(8): 1141-4$

[10] Tamon H, Ishizaka H, Araki T, Okazaki M. Control of mesoporous structure of organic and carbon aerogels. Carbon. 1998;36(9):1257-62.

[11] Yasuda H, Tamai H, Ikeuchi M, Kojima S. Extremely large mesoporous carbon fibers synthesized by the addition of rare earth metal complexes and their unique adsorption behaviors. Adv Mater. 1997;9(1):55-8.

[12] Ma T-Y, Liu L, Yuan Z-Y. Direct synthesis of ordered mesoporous carbons. Chem Soc Rev. 2013;42(9):3977-4003.

[13] Xu B, Duan H, Chu M, Cao G, Yang Y. Facile synthesis of nitrogendoped porous carbon for supercapacitors. J Mater Chem A. 2013;1(14):456570. 
[14] Atkinson JD, Rood MJ. Preparing microporous carbon from solid organic salt precursors using in situ templating and a fixed-bed reactor. Microp Mesop Mater. 2012;160(0):174-81.

[15] Zhou J, Yuan X, Xing W, Si W, Zhuo S. Capacitive performance of mesoporous carbons derived from the citrates in ionic liquid. Carbon. 2010;48(10):2765-72.

[16] Zhou QQ, Chen XY, Wang B. An activation-free protocol for preparing porous carbon from calcium citrate and the capacitive performance. Microp Mesop Mater. 2012;158(0):155-61.

[17] Sevilla M, Fuertes AB. A general and facile synthesis strategy towards highly porous carbons: carbonization of organic salts. J Mater Chem A. 2013;1(44):13738-41.

[18] Sevilla M, Fuertes AB. Direct Synthesis of Highly Porous Interconnected Carbon Nanosheets and Their Application as High-Performance Supercapacitors. ACS Nano. 2014;8(5):5069-78.

[19] Sevilla M, Fuertes AB. Hierarchical Microporous/Mesoporous Carbon Nanosheets for High-Performance Supercapacitors. ACS Appl. Mater. Interf., DOI: 10.1021/am508794f, 2015.

[20] ISO 9277:2010. Determination of the specific surface area of solids by gas adsorption - BET method. Second Edition of ISO 9277, ISO. Geneva; 2012. [21] Kruk M, Jaroniec M, Gadkaree KP. Nitrogen Adsorption Studies of Novel Synthetic Active Carbons. J Colloid Interface Sci. 1997;192(1):250-6.

[22] Kruk M, Jaroniec M, Sayari A. Application of Large Pore MCM-41 Molecular Sieves To Improve Pore Size Analysis Using Nitrogen Adsorption Measurements. Langmuir. 1997;13(23):6267-73. 
[23] Bassi PS, Randhawa BS, Jamwal HS. Mössbauer study of the thermal decomposition of iron(III) citrate pentahydrate. J Therm Anal. 1984;29(3):43944.

[24] Mansour SAA. Thermal decomposition of calcium citrate tetrahydrate. Thermochim Acta. 1994;233(2):243-56.

[25] Fuertes AB, Ferrero GA, Sevilla M. One-pot synthesis of microporous carbons highly enriched in nitrogen and their electrochemical performance. $\mathrm{J}$ Mater Chem A. 2014;2(35):14439-48.

[26] Pels JR, Kapteijn F, Moulijn JA, Zhu Q, Thomas KM. Evolution of nitrogen functionalities in carbonaceous materials during pyrolysis. Carbon. $1995 ; 33(11): 1641-53$.

[27] Schmiers H, Friebel J, Streubel P, Hesse R, Köpsel R. Change of chemical bonding of nitrogen of polymeric $\mathrm{N}$-heterocyclic compounds during pyrolysis. Carbon. 1999;37(12):1965-78.

[28] Yuan C, Zhang X, Wu Q, Gao B. Effect of temperature on the hybrid supercapacitor based on $\mathrm{NiO}$ and activated carbon with alkaline polymer gel electrolyte. Solid State Ionics. 2006;177(13-14):1237-42.

[29] Hou L, Lian L, Li D, Pang G, Li J, Zhang X, et al. Mesoporous Ncontaining carbon nanosheets towards high-performance electrochemical capacitors. Carbon. 2013;64(0):141-9.

[30] Yin J, Zhang D, Zhao J, Wang X, Zhu H, Wang C. Meso- and microporous composite carbons derived from humic acid for supercapacitors. Electrochim Acta. 2014;136(0):504-12. 
[31] Han Y, Liu S, Li D, Li X. Three-dimensionally Hierarchical Porous Carbon Creating High-performance Electrochemical Capacitors. Electrochim Acta. 2014;138(0):193-9.

[32] Chen H, Zhou M, Wang Z, Zhao S, Guan S. Rich nitrogen-doped ordered mesoporous phenolic resin-based carbon for supercapacitors. Electrochim Acta. (0).

[33] Ruiz V, Blanco C, Raymundo-Piñero $E$, Khomenko $V$, Béguin $F$, Santamaría R. Effects of thermal treatment of activated carbon on the electrochemical behaviour in supercapacitors. Electrochim Acta. 2007;52(15):4969-73.

[34] Raymundo-Piñero E, Cadek M, Béguin F. Tuning Carbon Materials for Supercapacitors by Direct Pyrolysis of Seaweeds. Adv Funct Mater. 2009;19(7):1032-9.

[35] Hsieh CT, Teng H. Influence of oxygen treatment on electric double-layer capacitance of activated carbon fabrics. Carbon. 2002;40(5):667-74.

[36] Lee Y-H, Chang K-H, Hu C-C. Differentiate the pseudocapacitance and double-layer capacitance contributions for nitrogen-doped reduced graphene oxide in acidic and alkaline electrolytes. J Power Sources. 2013;227(0):300-8.

[37] Wang D-W, Li F, Yin L-C, Lu X, Chen Z-G, Gentle IR, et al. NitrogenDoped Carbon Monolith for Alkaline Supercapacitors and Understanding Nitrogen-Induced Redox Transitions. Chemistry - A European Journal. 2012;18(17):5345-51.

[38] Xu B, Yue S, Qiao N, Chu M, Wei G. Easy preparation of nitrogen-doped porous carbon nanospheres and their application in supercapacitors. Mater. Lett. 2014;131(0):49-52. 
[39] Zhang M-y, Jin X-j, Zhao Q. Preparation of N-doped activated carbons for electric double-layer capacitors from waste fiberboard by K2CO3 activation. New Carbon Materials. 2014;29(2):89-95.

[40] Song Y, Hu S, Dong X, Wang Y, Wang C, Xia Y. A Nitrogen-doped Hierarchical Mesoporous/Microporous Carbon for Supercapacitors. Electrochim Acta. 2014;146(0):485-94.

[41] Jurewicz K, Pietrzak R, Nowicki P, Wachowska H. Capacitance behaviour of brown coal based active carbon modified through chemical reaction with urea. Electrochim Acta. 2008;53(16):5469-75.

[42] Seo M-K, Yang S, Kim I-J, Park S-J. Preparation and electrochemical characteristics of mesoporous carbon spheres for supercapacitors. Mater Res Bull. 2010;45(1):10-4.

[43] Galiński M, Lewandowski A, Stępniak I. Ionic liquids as electrolytes. Electrochim Acta. 2006;51(26):5567-80.

[44] Huang H-C, Huang C-W, Hsieh C-T, Teng H. Electric double layer capacitors of high volumetric energy based on ionic liquids and hierarchicalpore carbon. J Mater Chem A. 2014;2(36):14963-72.

[45] Shi M, Kou S, Yan X. Engineering the Electrochemical Capacitive Properties of Graphene Sheets in Ionic-Liquid Electrolytes by Correct Selection of Anions. ChemSusChem. 2014: Doi: 10.1002/cssc.201402275.

[46] Peng C, Wen Z, Qin Y, Schmidt-Mende L, Li C, Yang S, et al. ThreeDimensional Graphitized Carbon Nanovesicles for High-Performance Supercapacitors Based on Ionic Liquids. ChemSusChem. 2014;7(3):777-84. 
[47] Handa N, Sugimoto T, Yamagata M, Kikuta M, Kono M, Ishikawa M. A neat ionic liquid electrolyte based on FSI anion for electric double layer capacitor. J Power Sources. 2008;185(2):1585-8. 